of merit, not of authority. Sweeping beyond national frontiers, the community is linked by a strong network of communication through books, scientifie and learned periodicals, meetings, and a persuasive flow of travel and personal correspondence, in which much has been done to remove the barrier of language. Development now involves the fullest participation in this community of science and scholarship and it is suggested accordingly that present tensions underline the need to seek out and cherish those elements of modern life which bind men together across national and cultural frontiers. In the United States alone 66,000 persons participated in educational exchange during the year, 52,000 from 145 countries or territories coming to study or teach, and 14,000 Americans visiting 50 countries for similar tasks. Secondly, governments have demonstrated their ability to set political issues aside at selected points to co-operate effectively for the welfare of their peoples, and if international polities has not yet found practicable means for settling disputes, the field of politics could be reduced by steadily broadening the basis of co-operation on the long-range humane interests of man.

The President's review selects for emphasis the Polish science programme on which in May 1957, following a visit of Foundation representatives to Poland, grants of 300,000 dollars for purchase of scientific materials and supplies, books and periodicals and of 175,000 dollars for fellowships for younger Polish scientists to visit other countries were made. The new grants for Poland are concentrated on medical education, public health, the biological and medical sciences and agriculture, as the Ford Foundation, also at the invitation of the Polish Government, has initiated a programme in social sciences and humanities. Of the 25 fellowships awarded, 19 have already commenced study, most in the United States, but 4 in the United Kingdom, and grants-in-aid were also made to 21 more mature Polish scientists.

In referring again to the public health aspects of nuclear energy, the report suggests that the complicated and difficult problems which will accompany massive use of nuclear energy involve special responsibilities for the universities; the Foundation is accordingly supporting several broad programmes of special advanced training. That at the Now York University Institute of Industrial Medicine stresses the chemical and radiobiological toxicological problems of the nuclear energy industry, particularly quantitative aspects of environmental contamination ; at Harvard and at Pittsburgh problems of air-borne chemical and radiobiological contamination are stressed, while at Johns Hopkins University the primary emphasis is in the expanded Department of Biophysics: each of these institutions is receiving 500,000 dollars.

Dealing with the Foundation's operating programmes, the President reviews in some detail its world-wide study of the virus infections transmitted to men and domestic animals by the bite of arthropods. Under it more than 70 distinct viruses have been discovered, 37 of which have been shown to be members of one or other of three immunologically related families, 27 being located in South America, 24 in the Ethiopian region and 15 in the Oriental region, including India, Malaya, the Indonesian Archipelago, Indo-China and South China. He refers to the rapidity with which, in 1957 , following the discovery in India of an agent belonging to the Russian tick-borne complex of viruses, the etiology of the disease and its major epidemiological features were elucidated. This shows the utility of the Rockefeller Foundation's virus programme. A special appropriation of 100,000 dollars will assist the Indian Government with its vaccination campaign and enable Indian scientists to study vaccine production techniques in the United States.

Under the agricultural programme, now in its seventeenth year, the Mexican, Columbian, Chilean and Indian agricultural programmes, the last differing from the others in including direct connexion with a graduate school of agriculture and the correlation of the food crop research projects with the research and training activities of the school, will receive support. The Mexican and Columbian programmes have participated in the National Research Council project for preserving indigenous varieties of corn by systematically collecting samples of every extant variety in the High Andean region, Central America and Mexico, while all three Latin American units are co-operating in the international wheat rust nursery of the United States Department of Agriculture.

\title{
THE PLANT BREEDING STATION, NJORO, KENYA
}

\author{
By H. C. THORPE \\ Department of Agriculture, Kenya
}

\begin{abstract}
$\mathrm{T}$ HE new research laboratories of the Plant Breeding Station, Njoro, were opened on August 29, 1958, by the Speaker of the Kenya Legislative Council, Sir Ferdinand CavendishBentinck. $\mathrm{He}_{\Theta}$ was deputizing for the Minister of Agriculture, the Hon. Michael Blundell, who was unable to be present owing to illness. The ceremony was held in the presence of representatives of agricultural and milling interests, and of a large gathering of farmers from all over the country. After the opening, visitors were shown the field work in progress and conducted through the new laboratories where exhibits had been arranged demonstrating the various problems under investigation.
\end{abstract}

The building was designed and built by the Ministry of Works, in consultation with the Department of Agriculture, to cater for the special needs of the plant breeding team. The east wing houses the threshing room and cereal-selection laboratory, with space for the storage of sheaf material and packeted seed; special features are the provision of adequate well-lit benching for grain selection, and the arrangement of the layout for ease and efficiency of handling the breeding material. The west wing houses the pathology section, which deals with cereal diseases with special reference to wheat stem rust. The main body of the building consists of the administrative offices, a cereal chemistry laboratory, library, dark 
room, stores and service rooms, as well as private rooms for individual research officers. Much thought has gone into the planning of the layout, and the architect has designed a light and airy building of pleasing character, yet retaining its strictly functional purpose, for a total cost of $£ 15,000$.

The Station is situated at 7,100 ft. in the Kenya Highlands, virtually on the equator, in one of the main wheat-growing areas of the country. It is the headquarters of the Plant Breeding Section, and the main programme on wheat, barley and oats is concentrated there. The present staff of the section, including two plant breeders working on maize at subsidiary stations, comprises eight graduate officers and additional supporting staff.

History records that the early settlers in Kenya started growing wheat at the beginning of the century ; but that they suffered great loss due to rust attacks. Although a certain amount of desultory work was carried out from 1910 onwards, it was not until 1928 that wheat-breeding was put on an organized basis as a result of the visit of the late Sir Rowland Biffen, and the advice he gave to the Government to set up a wheat-breeding station. In that year the original station was built at Njoro and the late Capt. J. G. L. Burton, one of Biffen's pupils, was appointed to the first post of plant breeder. He was assisted by Mr. R. J. Lathbury, who later took charge when Burton retired. The Station has, until recently, remained virtually unchanged since those early days.

The present period of expansion dates from 1952-53 when development funds were first made available. The provision of improved facilities had become especially necessary due to the severe outbreaks of rust causing great damage to existing wheats and the urgent need to produce resistant varieties. The development has entailed recruitment of extra staff, purchase of additional land and specialized equipment, and now the construction of the new laboratories. It is especially satisfactory that farmers themselves, by agreeing to a cess on wheat, have made a substantial contribution to this development. Certain further projects, however, connected with rust pathology and maize breeding await the grant of special funds.

The plant breeding team is fortunate in being provided with such excellent new laboratories and modern facilities. Indeed, these are essential to the necessary intensification of the research programme to provide the rust-resistant wheats Kenya so urgently needs.

\section{THE GALACTIC SYSTEM AS A SPIRAL NEBULA}

$\mathrm{T}$ HE view that the Galaxy might have a spiral structure has been expressed almost since the first discoveries of such structure in nebulæ. It was not until 1951, however, that part of the galactic spiral structure was actually found. Work in this field has recently been summarized in a report on the progress of astronomy by J. H. Oort, F. T. Kerr and G. Westerhout (Mon. Not. Roy. Astro. Soc., 118, 379 ; 1958). The first definite discovery of spiral structure was accomplished by W. W. Morgan, S. Sharpless and D. E. Osterbrock, using the luminosity criteria for $O$ and $B$ stars developed by Morgan. They determined the distances of groups of these stars, and they showed that the regions of ionized hydrogen excited by the stars were arranged in long chains which formed parts of spiral arms. By a remarkable coincidence, radiation on $21-\mathrm{cm}$. wave-length from interstellar hydrogen was detected at about the same time as the visual work was done, and by 1954 a comprehensive picture of the spiral structure of the Galaxy could be assembled from radio observations. The importance of hydrogen-line radiation at $21 \mathrm{~cm}$. arises partly because of the transparency of inter. stellar dust to radio waves and partly because the study of this radio spectrum line gives discrimination in distance. Actual distances can only be inferred from radial velocities, and this involves the assumptions of circular motion and of equality of motions of stars and gas in any particular region of the Galaxy.

In order to transform radial velocities into distances, we must know how the circular velocity in the Galaxy varies with the distance from the galactic centre, and we must know the distance of the Sun from the centre. If we know the distance and circular velocity of the Sun we can derive, from the radio observations themselves, the variation of circular velocity with distance from the centre for distances smaller than that of the Sun. The distance from the Sun to the centre has been obtained directly from the study of the distribution of cluster-type cepheid variables concentrated near the centre. The best estimate obtained in this way is 8.2 kiloparsecs, the accuracy being limited by the uncertainty in the interstellar absorption and in the absolute magnitude of the variables. The circular velocity, and an independent estimate of the solar distance, can be obtained by combining radio observations with the constants of differential galactic rotation obtained from the proper motions and radial velocities of distant stars. The best available estimate of the circular velocity of the Sun is $215 \mathrm{~km}$. $/ \mathrm{sec}$. For regions of the Galaxy farther from the centre than the Sun we cannot determine the rotational velocities from radio observations, and we must rely on values computed from models of the Galaxy based on stellar densities. The rotation curve derived by $\mathbf{M}$. Schmidt from all available data shows a maximum of about $225 \mathrm{~km}$. $/ \mathrm{sec}$. at a distance of 7 kiloparsecs from the centre.

From profiles of the $21-\mathrm{cm}$. line one can now derive the density distribution of the neutral hydrogen in the Galaxy. Most of the hydrogen is confined to a flat disk, with a half-density whole-width of 220 parsecs. This hydrogen disk is remarkably flat; nowhere within 8 kiloparsecs from the centre do the points of maximum hydrogen density deviate by more than 75 parsecs from the galactic plane, although there are rather larger deviations in the outermost parts of the Galaxy. In contrast to this arrangement about the galactic plane the distribution in the plane shows great irregularities. The hydrogen outlines the spiral arms of the Galaxy. The Sun is situated near the inner edge of one arm; the latter probably contains the Orion association, and the whole arm is now called the Orion arm. Outside this, at a distance from the galactic centre of between 10 and 12 kilo- 